\title{
ROLE OF ULTRASOUND IN EVALUATION OF RETROPERITONEAL LESIONS
}

\author{
Harshita Pant ${ }^{1}$, Snehanshu Shukla², Rehan Ahmad ${ }^{3}$
}

${ }^{1}$ Assistant Professor, Department of Radiodiagnosis, MIMS, Barabanki, Uttar Pradesh.

${ }^{2}$ Assistant Professor, Department of Microbiology, MIMS, Barabanki, Uttar Pradesh.

${ }_{3}^{3}$ Associate Professor, Department of Radiodiagnosis, MIMS, Barabanki, Uttar Pradesh.

ABSTRACT
BACKGROUND
The retroperitoneum contains the adrenals, kidneys and ureters, the duodenal loop, pancreas, great vessels with their branches
and associated lymph node chains, ascending and descending portions of the colon including the caecum, the retroperitoneal
sonographic images are frequently degraded by bowel gas, thick muscles, fat, ribs, the lower lungs.

\section{AIMS AND OBJECTIVES}

To study the various features of retroperitoneal lesions by ultrasonography and assess its role.

\section{MATERIALS AND METHODS}

Fifty patients presenting with signs and symptoms suggestive of retroperitoneal pathology were evaluated over a period of 12 months using machine Siemens Sonoline Omnia/Siemens Sonoline G50 with 3.5 MHz convex and 5-10 MHz multifrequency linear transducer.

\section{OBSERVATIONS}

The maximum numbers of cases-17 (34\%) were of renal origin. This was followed by pancreatic lesion - 14 cases (28\%), USG correctly detected 46 out of 50 cases thus having an accuracy of $92 \%$ for the detection and evaluation of retroperitoneal lesions.

\section{CONCLUSIONS}

Ultrasound provides a safe, quick, reliable, non-invasive and cost effective tool for screening for retroperitoneum. We recommend ultrasound as the primary diagnostic tool for various retroperitoneal lesions.

\section{KEYWORDS}

Retroperitoneum, Ultrasound, Ultrasonography.

HOW TO CITE THIS ARTICLE: Pant H, Shukla S, Ahmad R. Role of ultrasound in evaluation of retroperitoneal lesions. J. Evolution Med. Dent. Sci. 2016;5(53):3563-3568, DOI: 10.14260/jemds/2016/821

\section{INTRODUCTION}

The retroperitoneum contains the adrenals, kidneys and ureters, the duodenal loop, pancreas, great vessels with their branches and associated lymph node chains, ascending and descending portions of the colon including the caecum.(1) The symptoms of retroperitoneal ailments are usually non-specific and physical examination is difficult. The sonographic images are frequently degraded by bowel gas, thick muscles, fat, ribs, the lower lungs.

Therefore, the present study was done to study the various features of retroperitoneal lesions by ultrasonography and assess its role.

\section{AIMS AND OBJECTIVES}

1. To study the various features of retroperitoneal lesions by ultrasonography and assess its role.

2. To correlate ultrasonographic findings with Cytological/

Financial or Other, Competing Interest: None.

Submission 05-05-2016, Peer Review 09-06-2016,

Acceptance 16-06-2016, Published 04-07-2016.

Corresponding Author:

Dr. Harshita Pant,

W/o. Dr. Snehanshu Shukla,

Plot-1, Basant Vihar Colony,

Behind St. Mary's Inter College,

Sector 14, Indira Nagar,

Lucknow-226016, Uttar Pradesh.

E-mail:drhpant@gmail.com

DOI: $10.14260 /$ jemds $/ 2016 / 821$ histopathological/laboratory findings/other radiological investigations (Wherever performed).

\section{MATERIAL AND METHODS}

The study was carried out in the Department of Radiodiagnosis, Himalayan Institute of Medical Sciences, Swami Ram Nagar, Dehradun, over a period of 12 months. Patients presenting with signs and symptoms suggestive of retroperitoneal lesions were included.

Ultrasound was done after clinical history and detailed clinical examination (After obtaining written informed consent).

\section{MACHINE}

Siemens Sonoline Omnia/Siemens Sonoline G50 with $3.5 \mathrm{MHz}$ convex and 5-10 MHz multifrequency linear transducer.

\section{SONOGRAPHY}

A firm, slow, graded compression technique was used. Patients with isolated renal calculus were excluded from the study. The findings of sonography were recorded and result correlated with relevant investigations (whichever performed).

\section{OBSERVATIONS}

Out of the fifty patients included in the study, 34 cases (68\%) were male and 16 cases (32\%) were female. 


\begin{tabular}{|c|c|c|}
\hline Symptom & No. of Cases & Percentage \\
\hline Pain abdomen & 33 & $66 \%$ \\
\hline Vomiting & 10 & $20 \%$ \\
\hline Fever & 09 & $18 \%$ \\
\hline Lump in abdomen & 09 & $18 \%$ \\
\hline Loss of appetite & 07 & $14 \%$ \\
\hline Fullness in abdomen & 06 & $12 \%$ \\
\hline Weight loss & 05 & $10 \%$ \\
\hline History of trauma & 03 & $06 \%$ \\
\hline Incidental & 02 & $04 \%$ \\
\hline \multicolumn{3}{|c|}{$\begin{array}{l}\text { Table 1: Symptoms Distribution } \\
\text { in Retroperitoneal Lesions }\end{array}$} \\
\hline
\end{tabular}

Other uncommon presenting complaints were jaundice, altered bowel habits, uncontrolled BP, primary amenorrhea, pruritus, lump elsewhere in body and leg oedema.

\begin{tabular}{|c|c|c|c|}
\hline $\begin{array}{c}\text { Sl. } \\
\text { No. }\end{array}$ & Organ & $\begin{array}{c}\text { No. of } \\
\text { Cases }\end{array}$ & Percentage \\
\hline 01 & Kidney & 17 & $34 \%$ \\
\hline 02 & Pancreas & 14 & $28 \%$ \\
\hline 03 & $\begin{array}{c}\text { Retroperitoneal Lymph } \\
\text { nodes }\end{array}$ & 7 & $14 \%$ \\
\hline 04 & Psoas muscle & 4 & $08 \%$ \\
\hline 05 & Caecum & 3 & $06 \%$ \\
\hline 06 & Adrenal & 3 & $06 \%$ \\
\hline 07 & Aorta & 2 & $04 \%$ \\
\hline \multicolumn{2}{|c|}{} & 50 & $100 \%$ \\
\hline \multicolumn{2}{|c|}{ Table 2: Distribution According to Organ of Origin } \\
\hline
\end{tabular}

The maximum numbers of cases - 17 (34\%) were of renal origin. Of these, renal cell carcinoma and congenital renal anomalies accounted for five cases (29\%) each, PUJ obstruction, pyonephrosis, renal trauma - 2 cases each and one case of simple renal cyst.

\begin{tabular}{|c|c|c|c|}
\hline Sl. No. & Feature & No. of Cases & Percentage \\
\hline 1 & $\begin{array}{c}\text { Size } \\
\text { Upto } 30 \mathrm{~mm} \\
31-60 \mathrm{~mm} \\
61-90 \mathrm{~mm} \\
>90 \mathrm{~mm}\end{array}$ & $\begin{array}{l}00 \\
03 \\
01 \\
01\end{array}$ & $\begin{array}{l}60 \% \\
20 \% \\
20 \%\end{array}$ \\
\hline 2 & $\begin{array}{l}\text { Appearance } \\
\text { Cystic } \\
\text { Solid } \\
\text { Complex } \\
\end{array}$ & $\begin{array}{l}00 \\
00 \\
05\end{array}$ & $100 \%$ \\
\hline 3 & $\begin{array}{c}\text { Echotexture } \\
\text { Hypoechoic } \\
\text { Hyperechoic } \\
\text { Isoechoic } \\
\text { Anechoic } \\
\text { Mixed }\end{array}$ & $\begin{array}{l}00 \\
00 \\
00 \\
00 \\
05\end{array}$ & $100 \%$ \\
\hline 4 & $\begin{array}{c}\text { Other } \\
\text { Associated } \\
\text { Findings }\end{array}$ & $\begin{array}{c}\text { Ipsilateral Renal Calculus } \\
\text { IVC Thrombosis } \\
\text { Adrenal Mass }\end{array}$ & $\begin{array}{l}01(20 \%) \\
01(20 \%) \\
01(20 \%)\end{array}$ \\
\hline \multicolumn{4}{|c|}{ Table 3: Sonographic Features of Renal Masses } \\
\hline
\end{tabular}

All the renal masses were greater than $3 \mathrm{~cm}$ and were heterogeneously hypoechoic with areas of necrosis within. One patient $(20 \%)$ had distended renal vein and IVC with hypoechoic area within suggestive of renal vein thrombosis.

One patient (20\%) had right suprarenal mass; however, the left suprarenal area could not be visualized on ultrasound in this patient due to poor acoustic window.

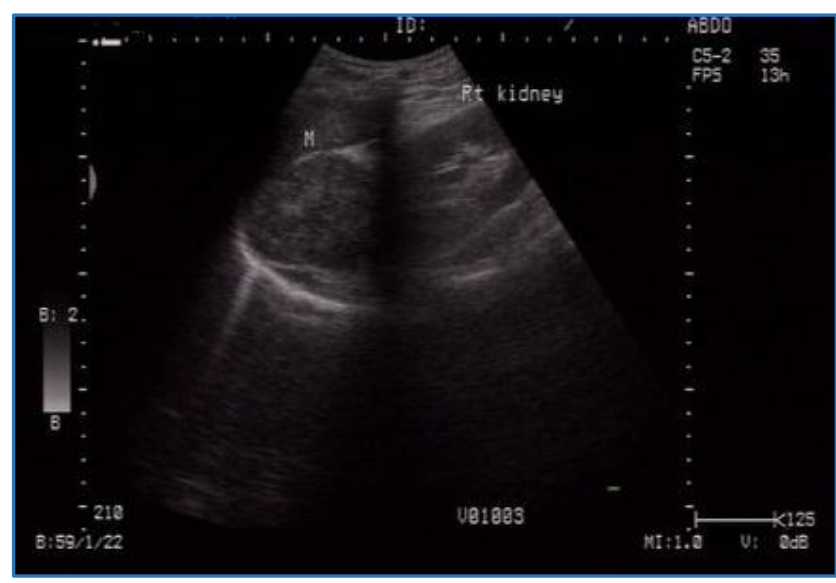

Fig. A: Heterogeneous mass at upper pole of right kidney

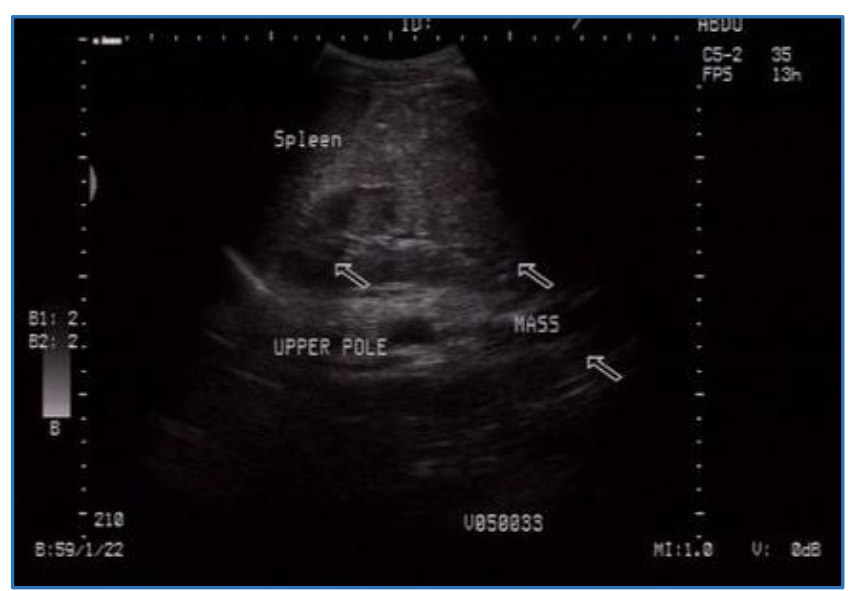

Fig. B: Heterogeneous mass at lower pole of left kidney infiltrating into adjacent structures

\section{Congenital Anomalies of Kidney}

Two patients of renal agenesis, one each of crossed fused ectopia, horse shoe kidney and ectopic kidney. The diagnosis was confirmed either on CT scan or IVP examination.

\section{Renal Trauma}

USG revealed a heterogeneous area at upper pole of right kidney suggestive of haematoma, confirmed on CT. The second patient revealed hyperechogenicity with an ill-defined outline at the mid and lower pole of left kidney suggestive of renal contusion. CECT confirmed the findings.

\section{Pyonephrosis}

USG revealed grossly enlarged kidney with gross dilatation of pelvicalyceal system, thinned out cortex. Mobile internal echoes were seen in one of these with multiple calculi in other patient. PCN followed by culture and sensitivity demonstrated streptococcus species and E. coli respectively.

\section{PUJ Obstruction}

Ultrasound showed grossly dilated pelvicalyceal system with abrupt narrowing at the lower end of renal pelvis. No associated calculus was seen. 


\section{Simple Renal Cortical Cysts}

Ultrasound demonstrated multiple rounded well-defined anechoic areas with posterior acoustic enhancement, thin wall with no calcification, at all the poles of right kidney, size 0.5 - 4 cms. No internal echoes, septations or mural nodule was noted.

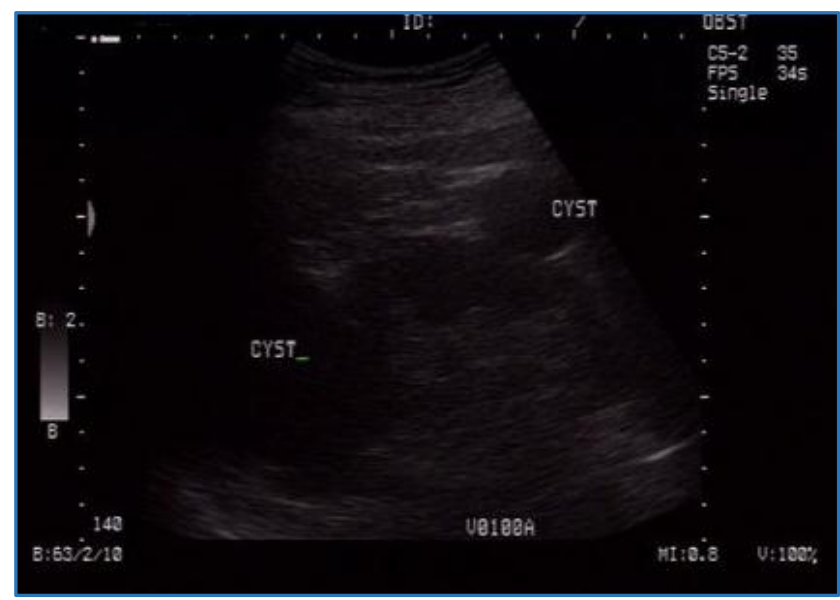

Fig. C: Left renal simple cortical cysts

The second common organ of origin for the retroperitoneal lesion was pancreas. Majority cases were of acute pancreatitis07 cases (50\%), followed by pseudo-pancreatic cyst 04 cases, pancreatic head mass 2 cases and chronic pancreatitis - 01 case. The ultrasound diagnosis was accurate in all except for two (29\%) out of 7 cases of acute pancreatitis, in whom the pancreatic visualization was not possible due to overlying bowel gases.

\begin{tabular}{|c|c|c|c|}
\hline $\begin{array}{c}\text { Sl. } \\
\text { No. }\end{array}$ & Feature & $\begin{array}{c}\text { No. of } \\
\text { Cases }\end{array}$ & Percentage \\
\hline 01 & Bulky Pancreas & 05 & $71 \%$ \\
\hline 02 & Peritoneal Fluid & 03 & $49 \%$ \\
\hline 03 & Pleural Effusion & 00 & $00 \%$ \\
\hline 04 & $\begin{array}{c}\text { Intrapancreatic/ } \\
\text { Peripancreatic Collection }\end{array}$ & 00 & $00 \%$ \\
\hline 05 & Pancreatic Calcification & 00 & $00 \%$ \\
\hline 06 & Pancreatic Duct Dilatation & 00 & $00 \%$ \\
\hline 07 & $\begin{array}{c}\text { Pancreas Obscured Due to } \\
\text { Bowel Gases }\end{array}$ & 02 & $29 \%$ \\
\hline \multicolumn{2}{|c|}{ Table 4: Sonographic Features of Acute Pancreatitis } \\
\hline
\end{tabular}

\section{Pseudopancreatic Cyst}

Showed thin walled anechoic area with well-defined margins in the lesser sac region containing internal echoes. The size varied from $13 \mathrm{cms}$ to $6 \mathrm{cms}$. Underlying pancreatic parenchyma was heterogeneous.

\section{Chronic Pancreatitis}

Showed atrophied pancreatic parenchyma with areas of calcification in the pancreatic bed. Pancreatic duct was dilated.

\section{Carcinoma Head of Pancreas}

Demonstrated dilated CBD and pancreatic duct with an hypoechoic area within the pancreatic head. No pancreatic parenchymal calcification was noted. The margins of the dilated pancreatic duct were regular.

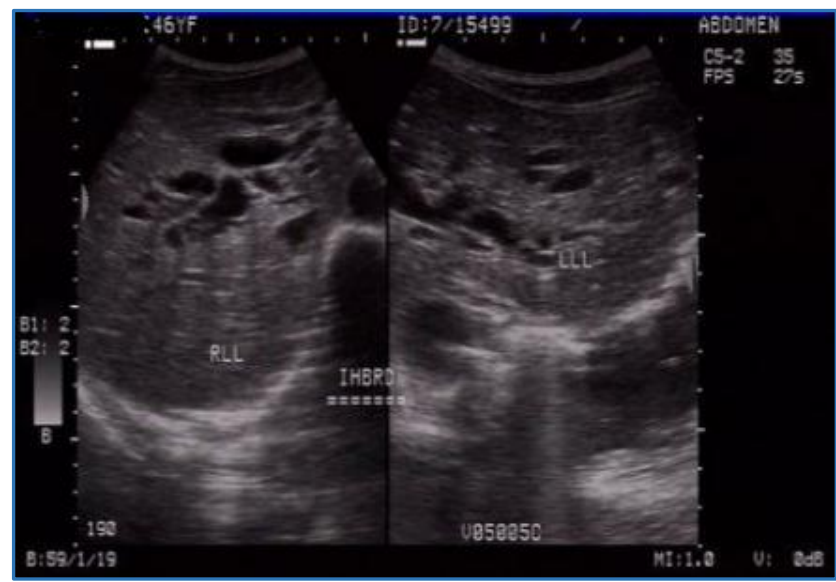

Fig. D: Bilobar intrahepatic biliary radicles dilatation secondary to pancreatic head mass

Retroperitoneal lymphadenopathy constituted the other main group of retroperitoneal lesion consisting a total of 7 cases $(14 \%)$.

\begin{tabular}{|c|c|c|c|}
\hline $\begin{array}{l}\text { Sl. } \\
\text { No. }\end{array}$ & Feature & $\begin{array}{l}\text { No. of } \\
\text { Cases }\end{array}$ & Percentage \\
\hline \multirow{7}{*}{01} & Site & & \\
\hline & Pre and Para-aortic & 07 & $100 \%$ \\
\hline & Pre and Paracaval & 06 & $86 \%$ \\
\hline & Periportal & 03 & $43 \%$ \\
\hline & Along the iliac vessels & 03 & $43 \%$ \\
\hline & Peripancreatic & 01 & $14 \%$ \\
\hline & Splenic hilum & 01 & $14 \%$ \\
\hline \multirow{4}{*}{02} & Size & & \\
\hline & $<3 \mathrm{~cm}$ & 02 & $29 \%$ \\
\hline & $3-5 \mathrm{~cm}$ & 03 & $43 \%$ \\
\hline & $>5 \mathrm{~cm}$ & 01 & $14 \%$ \\
\hline \multirow{4}{*}{03} & Shape & & \\
\hline & Round to oval (discreet) & & \\
\hline & Confluent mass encasing & 06 & $86 \%$ \\
\hline & $\begin{array}{c}\text { the retroperitoneal } \\
\text { vessels }\end{array}$ & 01 & $14 \%$ \\
\hline \multirow{3}{*}{04} & Margins & & \\
\hline & Smooth & 06 & $86 \%$ \\
\hline & Lobulated & 01 & $14 \%$ \\
\hline \multirow{4}{*}{05} & Appearance & & \\
\hline & Cystic & 00 & $00 \%$ \\
\hline & Solid & 07 & $100 \%$ \\
\hline & Complex & 00 & $00 \%$ \\
\hline \multirow{3}{*}{06} & Other associated findings & 05 & 71\% \\
\hline & Splenomegaly & 04 & $57 \%$ \\
\hline & Cholelithiasis & 01 & $14 \%$ \\
\hline \multicolumn{4}{|c|}{$\begin{array}{c}\text { Table 5: Sonographic Features in Retroperitoneal } \\
\text { Lymphadenopathy }\end{array}$} \\
\hline
\end{tabular}

Pre and para-aortic lymph node involvement was seen in all cases (100\%). All the lesions showed homogeneously hypo to isoechoic echotexture. There was no calcification or necrotic areas in any case. 


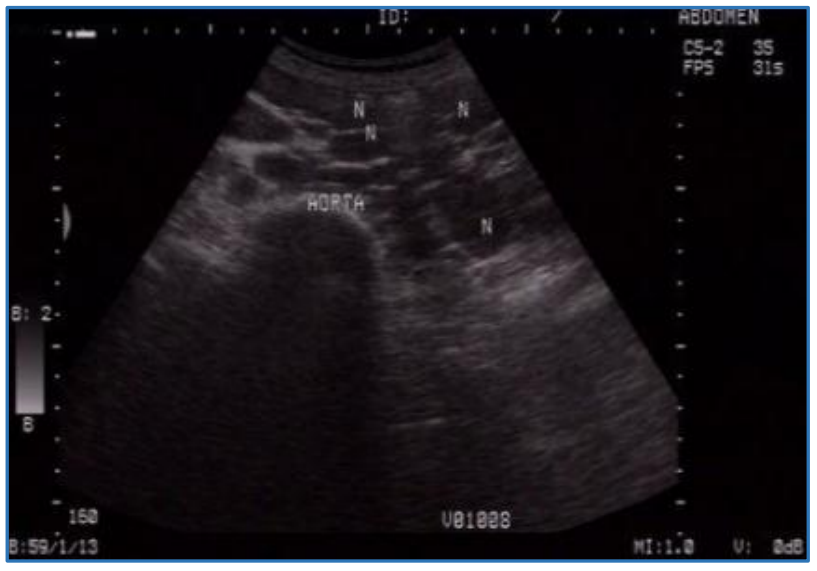

Fig. E: Multiple discreet round to oval pre and para aortic lymph nodes

\section{Psoas Abscess}

It appeared as an elongated anechoic area with internal echoes and well defined margins within the psoas muscle. Associated intraabdominal lymphadenopathy was found in 2 cases (50\%). USG guided drainage of the collection was done in all the four cases.

\section{Aorta}

Ultrasound demonstrated the dilatation of the abdominal aorta with hypoechoic area within suggestive of thrombus. The origin of right renal artery and superior mesenteric artery were involved in the first and second patient respectively. MRI and CT scan of the patient confirmed the findings.

\section{Caecal Mass}

Ultrasonography demonstrated asymmetric circumferential bowel wall thickening with central hyperechogenicity in right iliac fossa suggestive of caecal mass. Associated enlarged retroperitoneal lymph nodes were noted in two cases. FNAC from all the lesions showed features of adenocarcinoma.

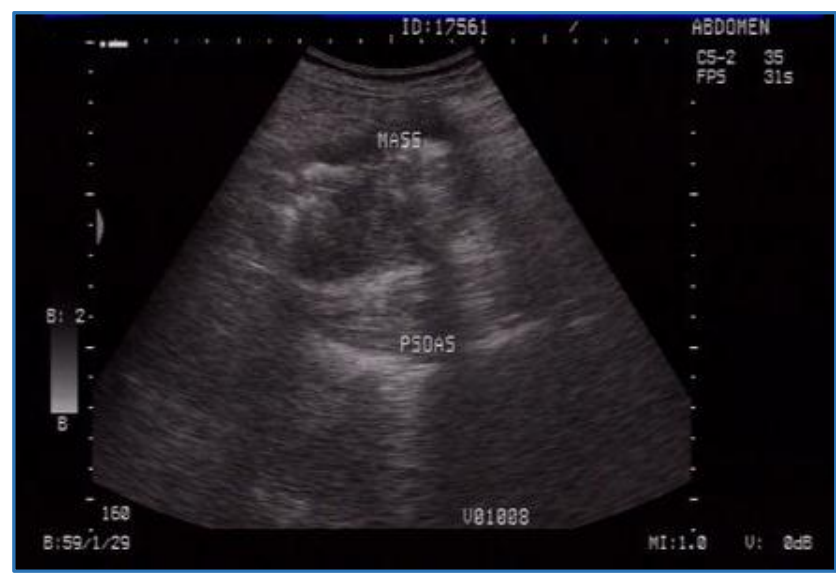

Fig. F: Caecal mass ventral to right psoas muscle

\section{Adrenals}

Out of three cases, one was a known case of carcinoma lung and the other was of round cell malignancy of mediastinum. The third case was later diagnosed as case of carcinoma lung on further radiological workup. The findings were confirmed on CT scan.

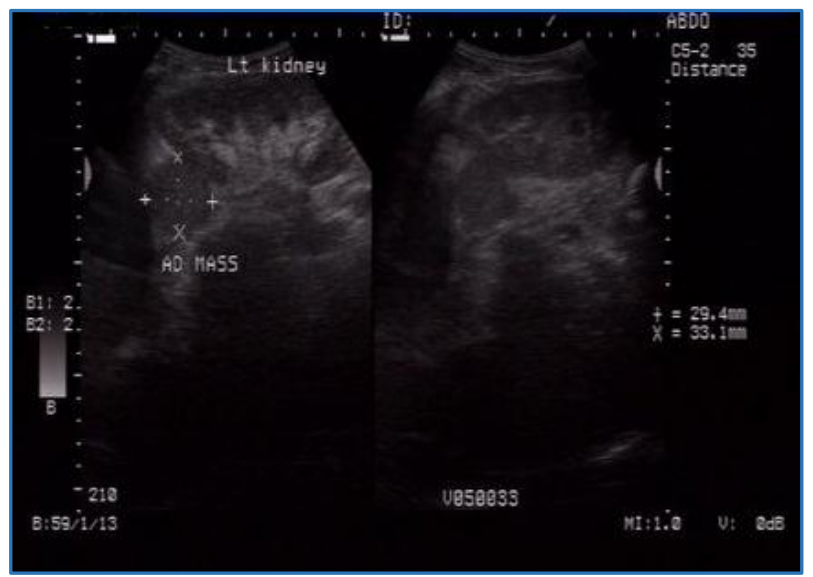

Fig. G: Left adrenal mass. Homogenous isoechic lesion adjacent to upper pole of left kidney

\section{DISCUSSION}

Kidney and pancreatic lesions constituted the bulk of pathology in retroperitoneum.

\section{Renal Mass}

All the cases were males with age ranging from 30 to 78 years with a mean age of 55 years. The large size masses were seen in patients of $>50$ years of age. The margins of the lesion were ill-defined and irregular in $4(80 \%)$ cases. However, in 1 case $(20 \%)$ the margins were well circumscribed. All the cases were heterogeneously hypoechoic with areas of necrosis within. No calcification was seen in the renal masses.

Gheissari found on sonography, solid tumours are found as solid isoechoic (86\%), hypoechoic or hyperechoic masses, usually without definite contour. Cystic lesions with more than two septae, internal calcification, septal thickening or nodularity are considered to be malignant lesions.(2) Dow, Choyke and Jennings et al indicated that CT depicts substantially more and smaller renal masses than does US, but is no better in the characterization of lesions.(3)

\section{Congenital Anomalies of Kidneys}

5 cases of congenital renal anomalies were detected. Two patients were of renal agenesis. One case each of crossed fused ectopia, horse shoe kidney and ectopic kidney.

\section{Renal Agenesis}

In first patient left kidney was not visualized, and there was a cystic area in the region of left seminal vesicle. CT scan of the patient confirmed agenesis of left kidney with associated ipsilateral seminal vesicle cyst. Ohgaki, Horiuchi and Oka et al studied that seminal vesicle cyst occurs as a result of congenital obstruction of the ejaculatory duct. (4)

In the other patient, IVU confirmed the diagnoses with non-visualization of right kidney.

\section{Horse Shoe Kidney}

The lower poles of both kidneys were rotated medially and were joined in front of the aorta and IVC by an hypoechoic band of solid tissue. There were no associated calculi or hydronephrosis. The finding was later confirmed by CT scan.

\section{Crossed Fused Ectopia}

In a 19-year-old female USG showed empty right renal fossa. Left kidney measured $13 \mathrm{~cm}$. The left kidney was otherwise 
found to be of normal shape and echotexture. IVU examination showed crossed fused ectopia. Thus, USG missed the diagnosis of crossed fused ectopia and misinterpreted it as right renal agenesis.

Ahmad R. observed that crossed fused renal ectopia is a rare renal anomaly with incidence of 1:1300-1:7500. Over bending and rotation of the caudal end of the embryo prevents the ureteric bud from merging with the ipsilateral metanephric blastema and thus is attracted towards the now more closer contralateral side.(5)

\section{Renal Trauma}

Two patients with renal trauma were included. Kay, Rosenfield and Armm studied the usefulness of gray scale ultrasonography in the evaluation of renal trauma and concluded that the extent of injury to the perirenal and pararenal regions was depicted better with ultrasound than with urography, nuclear medicine or angiography.(6) Thus, USG detected renal trauma in both the cases. It is quick and reliable diagnostic tool in emergency settings.

\section{Pyonephrosis}

Two patients were included in the study. In first one USG scan revealed grossly enlarged right kidney with gross dilatation of pelvicalyceal system, multiple calculi and mobile internal echoes within the dilated pelvicalyceal system. Overlying cortex was thinned out. Percutaneous nephrostomy with pus for culture demonstrated E. coli.

Subramanyam, Raghavendra and Bosnaik found ultrasound had an overall accuracy rate of $96 \%$ for detection of pyonephrosis. E. coli was the commonest organism cultured from the pyonephrotic kidneys. (7)

In the second patient, a 77-year-old male, no internal echoes were noted within the dilated pelvicalyceal system; however, PCN was done and pus for culture and sensitivity demonstrated streptococcus species. USG could not predict the possibility of pyonephrosis, as there were no internal echoes.

\section{PUJ Obstruction}

Two cases of PUJ obstruction were included in the study. Ultrasound showed grossly dilated pelvicalyceal system with abrupt narrowing at the lower end of renal pelvis. Final diagnosis of PUJ obstruction was made by IVU examination in one and CT scan in the other.

Alaleh Gheissari found that in cases of PUJ obstruction, ultrasound shows different degrees of dilatation of the renal pelvis and communicating calyces without a dilated ureter.(5)

\section{Simple Renal Cortical Cysts}

Ultrasound demonstrated multiple rounded well-defined anechoic areas with posterior acoustic enhancement at all the poles of right kidney,

\section{PANCREATIC LESIONS}

\section{Acute Pancreatitis}

Seven cases of acute pancreatitis were included in the study. Two were alcoholic while the one patient had trauma as the predisposing factor, two had biliary calculi. Rest of the two had no apparent predisposing factors. Steinberg and Tenner observed that gallstones are the most common cause of pancreatitis accounting for approximately 45 percent of cases.
Alcohol is the second most common cause accounting for 35 percent cases. ${ }^{(8)}$

Ultrasound suggested the diagnosis of acute pancreatitis in 5 out of 7 patients. In two (29\%) patients, pancreas and retroperitoneal area was obscured due to bowel gases.

In our study, ultrasound was a poor modality in detecting pleural effusion because of limitation of proper positioning and breath holding due to pain. Pleural effusions were missed in four patients out of the 06 , which underwent CT scanning and showed evidence of pleural effusion.

Badea found that the anteroposterior diameter at the level of the pancreas body exceeding $24 \mathrm{~mm}$ as well as a marked anterior convexity of the pancreas corresponds to a pathological increase in volume of the gland, a fact that is associated with oedema. The constituted necrosis will be delimited after about 4-6 weeks in the form of a pseudocyst.(9)

\section{Pseudopancreatic Cyst}

Four patients of clinically suspected pseudopancreatic cyst were included in the study. Ultrasound could confidently make the diagnosis of pseudopancreatic cyst in all the four cases. Ultrasound was recommended as the preferred follow-up modality for these patients as it is quick, non-invasive and reliable.

\section{Pancreatic Head Mass}

Ultrasound demonstrated bilobar IHBRD, dilated CBD and pancreatic duct in both cases with an hypoechoic area within the pancreatic head. The size of the mass was $2-3 \mathrm{cms}$. These findings were further confirmed on CT scan and MRI respectively.

Costa, Tassinari and Bondi et al found that in small tumours (Less than $2 \mathrm{~cm}$ ) the "indirect signs," such as dilatation of main pancreatic duct and/or common bile duct are well visualized.(10)

Miura, Takada and Hodaka et al observed that the accuracy of conventional US for diagnosing pancreatic tumour is only $50-70 \% .(11)$

\section{Retroperitoneal Lymphadenopathy}

Seven cases of retroperitoneal lymphadenopathy were studied. All the cases were proved out to be lymphoma, mainly follicular type. Thus, ultrasound is quite sensitive in demonstrating enlarged retroperitoneal lymph nodes. This is also a field where ultrasound is quite helpful for image-guided FNAC.

\section{Psoas Abscess}

Ultrasound demonstrated elongated anechoic cystic area in the substance of the psoas muscles with internal echogenic debris. Ultrasound guided drainage of the abscess was done in all the cases. Thus, ultrasound was helpful diagnostically as well as therapeutically.

Merdina, Mitusova and Sovetova studied 64 patients and concluded that is helpful in answering questions as what surgical access should be chosen and what scope of surgical intervention made.(12)

\footnotetext{
Aorta

McGregor, Pollock and Anton et al found ultrasonography was useful in distinguishing aneurysms from other conditions and there was a high degree of correlation between size measured by scanning and operative size.(13)
} 


\section{Adrenal Lesions}

Out of three cases, two were known cases of primary lung carcinoma and round cell mediastinal malignancy. The third case also proved out to be harbouring a primary in the lung on further radiological workup.

Dunnick observed that the most common indication for adrenal imaging is the detection of metastatic disease. An adrenal metastasis cannot be distinguished clearly from benign lesions such as an adenoma, haematoma, pseudocyst or inflammatory mass on the basis of its morphology.(14)

The lesions were further confirmed on CT scan in all the cases. The lesions were bilateral in two cases; however, USG had missed the left adrenal lesion in one out of these two cases. The third case had unilateral right adrenal mass. Thus, ultrasound was sensitive to pick up the adrenal masses in our study, which were of quite large size. However, the left adrenal lesion measuring approximately $2 \times 1.5 \mathrm{~cm}$ on CT scan was missed on ultrasound.

Yamakita, Yasuda and Goshima et al found US is better than CT for demonstrating the intratumorous characteristics, the relationship between the tumour and the surrounding organs and the organ from which large tumours arise, such as pheochromocytoma. On the other hand, CT is better able to detect small adrenal tumours. ${ }^{(15)}$

Thus, USG correctly detected 46 out of the total 50 cases having an accuracy of $92 \%$ for the detection and evaluation of retroperitoneal lesions. The final diagnosis was confirmed by FNAC/histopathological findings in 13 cases, laboratory findings in 15 cases and other radiological investigations in 22 cases.

\section{CONCLUSION}

Ultrasound is a good modality for screening of renal masses. For pyonephrosis USG is a good diagnostic tool as well as helpful for guidance for drainage or aspiration. Ultrasound is accurate and sensitive modality for detection of enlarged retroperitoneal lymph nodes. It is also helpful in guiding FNAC from them for the final cytological diagnosis. For psoas abscess, USG is a sensitive modality diagnostically as well as therapeutically by carrying out image-guided drainage procedure and also in the follow-up of these patients.

The sensitivity of ultrasound for diagnosis of pancreatic lesions falls due to poor echo window caused by bowel gases, especially in acute pancreatitis. However, it is a non-invasive and reliable tool for diagnosis and follow-up of the complications of acute pancreatitis like pseudo-pancreatic cyst.

Ultrasound is the mainstay of radiological investigation for patients presenting with symptoms related to abdominal pathology. It provides a safe, quick, reliable, non-invasive and cost effective tool for screening for various abdominal pathologies including retroperitoneum.
In view of these findings, we recommend ultrasound as the primary diagnostic tool for various retroperitoneal lesions. It is also recommended as a tool of therapeutic significance as well as for the follow-up of patients.

\section{REFERENCES}

1. Cosgrove DO, Dubbins PA. The peritoneum and retroperitoneum. In: Meire HB, Cosgrove DO, Dewberry $\mathrm{KC}$, et al. (eds.) Abdomen and general ultrasound. $2^{\text {nd }}$ ed. London: Churchill Livingstone, 2001:460.

2. Gheissari A. The place of ultrasound in renal medicine. Saudi J Kidney Dis Transpl 2006;17(4):540-8.

3. Dow JCA, Choyke PL, Jennings SB, et al. Small $(<3-\mathrm{cm})$ renal masses: detection with CT versus US and pathologic correlation. Radiology 1996;198(3):785-8.

4. Ohgaki $\mathrm{K}$, Horiuchi $\mathrm{K}, \mathrm{Oka} F$, et al. A case of seminal vesicle cyst associated with ipsilateral renal agenesis diagnosed during an investigation of perineal pain. J Nippon Med Sch 2008;75(2):122-6.

5. Ahmad R. A rare association of crossed fused renal ectopia. BMC Nephrol 2007;8:5.

6. Kay CJ, Rosenfield AT, Armm M. Gray-scale ultrasonography in the evaluation of renal trauma. Radiology 1980;134(2):461-6.

7. Subramanyam BR, Raghavendra BN, Bosniak MA, et al. Sonography of pyonephrosis: a prospective study. AJR Am J Roentgenol 1983;140(5):991-3.

8. Steinberg W, Tenner S. Acute pancreatitis. N Engl J Med 1994;330:1198-210.

9. Badea R. Ultrasonography of acute pancreatitis-an essay in images. Rom J Gastroenterol 2005;14(1):83-9.

10. Costa PL, Tassinari M, Bondi A, et al. Pancreatic head mass: what can be done? Diagnosis: ultrasonography. J Pancreas 2000;1(3 Suppl):91-4.

11. Miura F, Takada T, Amano H, et al. Diagnosis of pancreatic cancer. HPB 2006;(5):337-42.

12. Merdina EV, Mitusova GM, Sovetova NA. Ultrasound diagnosis of retroperitoneal abscesses in spinal tuberculosis. Probl Tuberk 2001;4:19-21.

13. McGregor JC, Pollock JG, Anton HC. The diagnosis and assessment of abdominal aortic aneurysms by ultrasonography. Ann R Coll Surg Engl 1976;58(5): 388-92.

14. Dunnick NR. Adrenal imaging: current status. AJR Am J Roentgenol 1990;154(5):927-36.

15. Yamakita N, Yasuda K, Goshima E, et al. Comparative assessment of ultrasonography and computed tomography in adrenal disorders. Ultrasound Med Biol 1986;12(1):23-9. 